\title{
Long-term durable benefit after whole lung lavage in pulmonary alveolar proteinosis
}

\author{
M. Beccaria*, M. Luisetti*, G. Rodi", A. Corsico*, M.C. Zoia*, S. Colato*, P. Pochetti*, A. Braschi\#, \\ E. Pozzi*, I. Cerveri*
}

Long-term durable benefit after whole lung lavage in pulmonary alveolar proteinosis. M. Beccaria, M. Luisetti, G. Rodi, A. Corsico, M.C. Zoia, S. Colato, P. Pochetti, A. Braschi, E. Pozzi, I. Cerveri. (C) ERS Journals Ltd 2004.

ABSTRACT: Whole lung lavage (WLL) is still the gold-standard therapy for pulmonary alveolar proteinosis (PAP). The few studies on the duration of the effect of WLL, belonging to a rather remote period, show significant but transient benefits.

In 21 patients with idiopathic PAP, the duration of any benefit and, in 16 of them, the time course of lung function improvement (at baseline, 1 week, 6 months, 1 yr and then every 2 yrs after WLL) were evaluated. The present WLL technique takes longer, is invasively monitored and partially modified with respect to past techniques.

More than $70 \%$ of patients remained free from recurrent PAP at 7 yrs. The bulk of the improvement in spirometric results was almost completely gained in the immediate post-WLL period due to the efficient clearance of the alveoli. At a median of 5 yrs, recovery of diffusing capacity of the lung for carbon monoxide was incomplete $(75 \pm 19 \%$ of the predicted value) and there were residual gas exchange abnormalities (alveolar to arterial oxygen tension difference $3.6 \pm 1.5 \mathrm{kPa}(27 \pm 11 \mathrm{mmHg})$ ) and exercise limitation, probably explained by engorgement of lymphatic vessels.

In conclusion, whole lung lavage for idiopathic pulmonary alveolar proteinosis is currently a safe procedure in an experienced setting, and provides long-lasting benefits in the majority of patients.

Eur Respir J 2004; 23: 526-531.
*Respiratory Diseases Division, and ${ }^{*}$ Anaesthesiology and Intensive Care Unit, Istituto di Ricovero e Cura a Carattere Scientifico, Policlinico S. Matteo, University of Pavia, Pavia, Italy.

Correspondence: I. Cerveri

Division of Respiratory Diseases

IRCCS Policlinico S. Matteo

via Taramelli 5

27100 Pavia

Italy

Fax: 390382423150

E-mail: i.cerveri@libero.it

Keywords: Bronchoalveolar lavage follow-up studies pulmonary alveolar proteinosis respiratory function tests

Received: September 112003

Accepted after revision: November 242003
Idiopathic pulmonary alveolar proteinosis (PAP) is a rare disease of unknown cause characterised by the presence of massive quantities of proteinaceous eosinophilic periodic acid/ Schiff-positive material in the alveoli [1], and by an excess of surfactant components in lung fluid [2]. Whole lung lavage (WLL), introduced by RAMIREZ [3] in the late 1960s, is still the gold-standard therapy. Indeed, this technique has been much improved over the years, thus enhancing effective removal of material from the alveoli [4].

As usually happens with rare disorders, there are only a few published reports of long-term studies including $>10$ subjects, assessed and followed in a single clinical centre. Based on a review of such series retrieved from the literature, it was recently concluded that, within 5 yrs of diagnosis, almost two-thirds of the evaluable published cases had undergone WLL, with $>80 \%$ attaining significant, albeit only transient, benefit [5]. Nevertheless, the authors emphasised that, in the absence of a randomised trial or even a formal prospective study, the true impact of massive removal of lung surfactant, i.e. WLL, on the natural history of PAP is difficult to ascertain. Moreover, the reports reviewed spanned several decades and most patients were diagnosed and treated before the 1990s, whereas peri- and post-operative WLL procedures and the global management of the disease subsequently improved substantially [4-6].

It has recently been shown that granulocyte-macrophage colony-stimulating factor (GM-CSF) appears to benefit a

$\overline{\text { For editorial comments see page } 503 .}$ subset of adult patients with PAP, and may represent an alternative to WLL in treating this disease. Pending more definitive approaches to manipulation of the GM-CSF/antiGM-CSF antibody balance, the present authors believe that information regarding established therapies is particularly needed [7]. To the present authors' knowledge, there have been no reports in the 1990s dealing with series of PAP patients prospectively studied using lung function parameters following WLL. Taking advantage of a WLL programme established 12 yrs ago, in 1990, in Pavia Hospital (Pavia, Italy), the only centre in Italy with such a programme, lung function and gas exchange were evaluated at scheduled time points in the long-term follow-up of a relatively large series of PAP patients.

The aim of the present study was to determine the impact of WLL, focusing particularly on the duration of any benefit in order to evaluate whether this was transient or long-lasting. Moreover, exploiting the long-term follow-up with simultaneous measurements of different respiratory parameters, the time course of functional improvement after WLL was investigated in an attempt to shed light on the mechanism by which this technique acts.

\section{Methods}

\section{Patients and study design}

During the 12-yr period 1990-2001, a series of 21 patients from among those subjects with idiopathic PAP referred to 
Pavia Hospital from other hospitals were treated with WLL. The characteristics of these 21 patients are reported in table 1 . Owing to recurrence of the disease, three patients underwent more than one WLL. The criteria adopted in Pavia Hospital for performing WLL were progressive worsening of the alveolar to arterial oxygen tension difference $\left(\mathrm{PA}-\mathrm{a}, \mathrm{O}_{2}\right)$ and the reported pulmonary symptoms with severe limitation of daily activities. The diagnosis of PAP had been made by either transbronchial (four patients) or open lung (seven patients)/video-assisted (three patients) thoracoscopic biopsy or based on consistent bronchoalveolar lavage and highresolution computed tomography (HRCT) features (seven patients) [5]. In 10 of the 14 patients who had undergone biopsy, histological material was obtained from other hospitals for consultation by a local pathologist; in all cases, HRCT images produced in other institutions were reviewed by the local radiologist. Careful clinical and laboratory screening were performed at the time of enrolment in order to designate the PAP as idiopathic.

After WLL, information was collected on the duration of benefit in all of the 21 patients; 16 of them agreed to participate in a long-term lung function study. Disease recurrence was defined as the recurrence, or significant progression, of respiratory symptoms attributable to PAP, or the application of further therapeutic interventions such as repeated lavage; episodes of infection were not considered to represent disease recurrence. The 16 patients included in the lung function study were scheduled for examination 1 week, 6 months, $1 \mathrm{yr}$ and then every $2 \mathrm{yrs}$ after WLL. Three of these patients interrupted the lung function study, after 3,5 and $5 \mathrm{yrs}$, due to their living a long way from Pavia Hospital. The three patients who underwent more than one WLL interrupted the lung function study at their second WLL, which occurred 2, 3 and 3 yrs after the first WLL. Overall, 11 patients completed $\geqslant 3$ yrs of lung function follow-up; the last examination among these 11 patients was at a median time of $5 \mathrm{yrs}$ after WLL.

\section{Table 1.-Patient characteristics}

\begin{tabular}{lcccc}
\hline Patient & Age & Sex & Smoking & $\begin{array}{c}\text { Cumulative } \\
\text { cigarette } \\
\text { consumption } \\
\text { pack-yrs }\end{array}$ \\
pors & yrs of WLL &
\end{tabular}

\begin{tabular}{lccccc}
\hline 1 & 35 & M & Previous & 15 & 1990 \\
2 & 26 & M & No & 0 & 1993 \\
3 & 46 & F & No & 0 & 1990,1992, \\
& & & & & 1993,1994 \\
4 & 44 & M & Previous & 40 & 1993,1995 \\
5 & 43 & M & Previous & 23 & 1993,1995 \\
6 & 56 & M & No & 0 & 1995 \\
7 & 36 & M & Yes & 40 & 1995 \\
8 & 46 & M & Previous & 65 & 1995 \\
9 & 30 & F & Previous & 10 & 1996 \\
10 & 35 & M & Yes & 30 & 1998 \\
11 & 18 & F & No & 0 & 1998 \\
12 & 38 & M & Previous & 34 & 1999 \\
13 & 63 & M & No & 0 & 2001 \\
14 & 60 & M & Previous & 4.5 & 2001 \\
15 & 34 & M & Yes & 7.5 & 2001 \\
16 & 46 & F & Previous & 20 & 2001 \\
17 & 17 & M & No & 0 & 2001 \\
18 & 23 & M & No & 0 & 2002 \\
19 & 46 & M & Previous & 75 & 2002 \\
20 & 47 & M & Previous & 40 & 2002 \\
21 & 71 & M & Previous & 137 & 2002 \\
\hline
\end{tabular}

WLL: whole lung lavage; M: male; F: female.
All subjects gave their consent prior to entering the study, which was approved by the Ethical Committee of Pavia Hospital.

\section{Whole lung lavage}

The present WLL technique $[4,8]$ is a modification, in an attempt to improve safety and efficacy, of the procedure previously reported in the literature $[3,9,10]$. The present procedure is performed with the patient in lateral decubitus. Differently from previous reports, it was decided to ventilate the dependent lung and lavage the nondependent lung. This choice reduces blood flow to the lavaged lung (thus giving a better ventilation/perfusion ratio) and allows easy access to the same lung for chest wall percussion. After placement of a left-sided double-lumen endotracheal tube, the patient was positioned in right lateral decubitus in order to lavage the smaller left lung first. Only in a few patients, whose right lung was much more compromised than the left one, was right lung lavage performed first, with the patient positioned first in left lateral decubitus. Before lavage, a 20 -min test of one-lung ventilation of the dependent lung was performed, with a high inspiratory oxygen fraction (up to 1) and low positive endexpiratory pressure, while the nondependent lung was actively deflated and degassed as much as possible, in order to reproduce the worst possible condition that could occur during the lavage. In this way, the safety of the procedure was tested in each individual patient. After the test, the lavage was started with tidal volumes of saline warmed to body temperature, both delivered and drained by gravity through a large-bore tubing system. Fluid tidal volume movements were continuously monitored by a scale incorporated into the bed. When the outflow, initially milky, became clear, chest wall percussion, which restarts and greatly enhances the removal of proteinaceous material, was added. Lavage and percussion were continued until the outflow fluid became definitively clear, which may take $\sim 3 \mathrm{~h}$ and a total of $25-40 \mathrm{~L}$ saline for a single lung. After the lavage, as much fluid as possible was drained and then careful thorough suction was applied using fibreoptic bronchoscopy; ventilation with positive end-expiratory pressure was started, first in the lateral decubitus and then in the supine position. The lavage of the second lung was performed with the patient in the opposite lateral decubitus, using the same procedure and after the above-described test of one-lung ventilation tolerance. The timing of the lavage of the second lung depended on the recovery of the lung lavaged first. In all but one patient, the lavage of the second lung was performed on the same day, $\sim 1 \mathrm{~h}$ after completion of the first lavage. The only patient in whom the second lavage was performed the following day had developed cardiac arrhythmias, subsequently diagnosed as a Wolff-Parkinson-White syndrome, during the first lavage procedure. WLL was performed under conditions of general anaesthesia and muscle paralysis and took 5-10 h. The standard monitoring included electrocardiography, invasive blood pressure, central venous pressure, pulmonary artery pressure, thermodilution cardiac output, pulse oximetry, airway pressure, airflow, respiratory mechanics, oesophageal stethoscope, body weight and internal temperature. During WLL, salbutamol was administered by continuous intravenous infusion in order to prevent possible lavage-induced bronchospasm, which might reduce the efficacy of the procedure. When necessary, the potential electrolyte disorders due to the dialytic effect of WLL (mainly, hypokalaemia and metabolic acidosis) were compensated for by appropriate therapy. Ventilatory assistance lasted $\sim 24 \mathrm{~h}$ after WLL; the total duration of hospital inpatient stay was $\sim 5$ days. At the time of WLL, none of the patients exhibited opportunistic 
pathogens. The bronchoalveolar lung fluid was systematically cultured. One patient had had a diagnosis of Nocardia spp. infection $1 \mathrm{yr}$ before the diagnosis of PAP had been made and one developed pulmonary tuberculosis 6 months after WLL. All of the patients were treated with a third-generation cephalosporin after WLL.

\section{Measurements made before and after whole lung lavage}

At baseline and during follow-up, patients underwent spirometry, determination of lung volumes and diffusing capacity of the lung for carbon monoxide ( $D \mathrm{~L}, \mathrm{CO})$, arterial blood gas analyses and treadmill exercise testing; exercise testing was not scheduled at the 1-week evaluation.

Spirometry with a helium analyser (Pulmonet III; Sensormedics, Anheim, CA, USA) was used to measure lung function. Forced expiratory volume in one second, forced vital capacity (FVC) and slow vital capacity were determined according to American Thoracic Society criteria [11]. Lung volumes were measured by multibreath helium-dilution. Total lung capacity was obtained from the sum of the functional residual capacity and inspiratory capacity. Predicted values for spirometry and lung volumes were obtained from QUANJER et al. [12].

Single-breath $D$ L, CO was measured at least in duplicate (Transferscreen II; Jaeger, Würzburg, Germany) and compared to the predicted values of COTES et al. [13].

Arterial blood samples were taken at rest from a radial artery under room air conditions. Arterial oxygen $\left(\mathrm{Pa}, \mathrm{O}_{2}\right)$ and carbon dioxide tensions were measured using an automatic blood gas analyser (Ciba Corning Diagnostics Corp., Hedfield, MA, USA) and $\mathrm{PA}-\mathrm{a}, \mathrm{O}_{2}$ calculated using a simplified gas equation.

Exercise tolerance was assessed throughout follow-up, except at 1 week, in patients whose $\mathrm{PaO}_{2}$ was $\geqslant 8.0 \mathrm{kPa}$ $(60 \mathrm{mmHg})$. Treadmill exercise testing (modified Bruce protocol) was performed, starting from step $0\left(2.7 \mathrm{~km} \cdot \mathrm{h}^{-1}\right.$ for $3 \mathrm{~min})$ to step $0.5\left(2.7 \mathrm{~km} \cdot \mathrm{h}^{-1}\right.$ for $3 \mathrm{~min}, 5 \%$ incline), step $1\left(2.7 \mathrm{~km} \cdot \mathrm{h}^{-1}\right.$ for $3 \mathrm{~min}, 10 \%$ incline $)$ and up to step 4 , with a $2 \%$ increase in incline and increased speed at each step (step 2: $4 \mathrm{~km} \cdot \mathrm{h}^{-1}$; step $3: \mathrm{km} \cdot \mathrm{h}^{-1}$; step $4: 6.8 \mathrm{~km} \cdot \mathrm{h}^{-1}$ ) [14]. The test was interrupted at the onset of breathlessness, when the fall in arterial oxygen saturation $\left(\mathrm{Sa}, \mathrm{O}_{2}\right)$ was $>5 \%$ or when the cardiac frequency reached $80 \%$ of the maximal predicted value. $\mathrm{Sa}, \mathrm{O}_{2}$ and cardiac frequency were measured using a pulse oximeter (Oxyshuttle; Sensormedics).

\section{Statistical analysis}

Time-to-treatment-failure analysis was calculated using the Kaplan-Meier method with disease recurrence used as the definition of an event; patients were censored at the time of the last follow-up. Analysis of repeated measures (multivariate analysis of variance) was used to test for significant changes in parameters with time; critical changes with time were analysed using Tukey's honestly significant difference test.

Additionally, differences between parameters before and 1 week after WLL and at the last examination were tested using a paired t-test. A p-value of $<0.05$ was considered significant; all tests were two-sided. Results are reported as mean \pm SD.

\section{Results}

Before WLL, 12 of the 21 patients complained of severe dyspnoea at rest and the remainder had a subjective perception of reduced exercise tolerance with severe limitation of daily activities. Blood gas exchange was characterised by moderate-to-severe hypoxaemia accompanied by mild hypocapnia or normocapnia with a very high $P A-a, O_{2}(6.3 \pm 2.0 \mathrm{kPa}$ $(47 \pm 15 \mathrm{mmHg}))$. Ten patients were receiving oxygen therapy because of persistent respiratory failure. One patient underwent WLL four times between 1990 and 1994 and two patients underwent two WLLs within 3 yrs. After WLL, no other patients showed significant progression of respiratory symptoms attributable to PAP. After 1995, no patients required more than one WLL. No major adverse effects occurred during WLL or during the immediate postoperative care. More than $70 \%$ of patients remained free from recurrent PAP manifestations at 7 yrs (fig. 1).

The 16 patients included in the lung function follow-up study showed, at baseline, a moderate restrictive pattern with a disproportionate decrease in DL,CO (table 2). Eight patients who were not severely hypoxaemic underwent exercise testing. Exercise tolerance in these patients was poor, the mean total distance covered before exercise interruption, due to dyspnoea and/or a change in $\mathrm{Sa}, \mathrm{O}_{2}$ of $>5 \%$, being only $239 \pm 152 \mathrm{~m}$.

One week after WLL, a significant improvement in FVC was observed (table 2). This parameter continued to show improvement $(\mathrm{p}<0.05,1$ yr versus 1 week post hoc comparison), with a near-complete recovery in almost all patients at $1 \mathrm{yr}$. The overall trend was highly significant $(\mathrm{p}<0.0001)$ (fig. 2).

$D \mathrm{~L}, \mathrm{CO}$ showed different behaviour: there was no increase by 1 week (table 2 ) followed by a steeper improvement over the next 6 months $(\mathrm{p}<0.05,6$ months versus 1 week post hoc

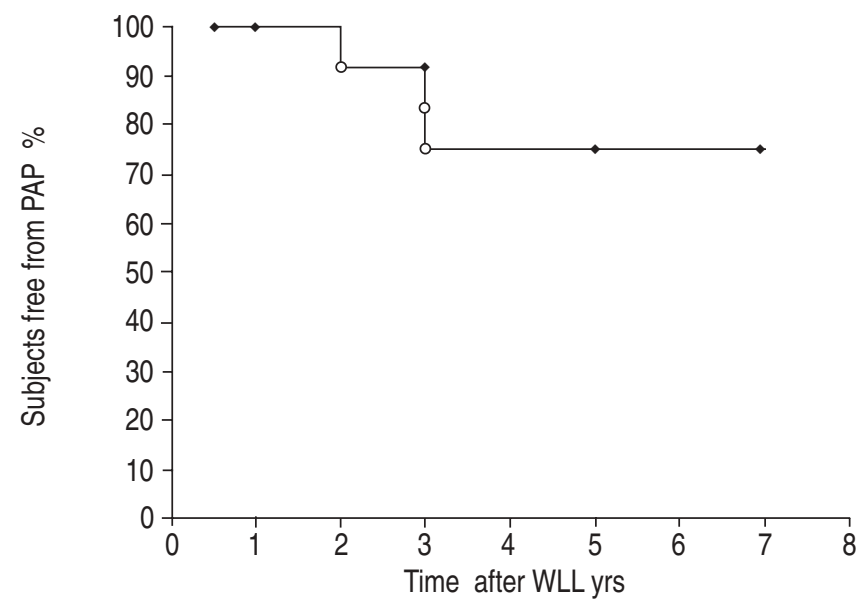

Fig. 1.-Cumulative proportion of subjects free from recurrent pulmonary alveolar proteinosis (PAP) after whole lung lavage (WLL). In the analysis, disease recurrence was an event $(\bigcirc)$, and patients were censored at the time of the last follow-up $(\bullet)$.

Table 2.-Immediate improvement after whole lung lavage $(\mathrm{WLL})^{\#}$

\begin{tabular}{lccc}
\hline & Baseline & 1 week after WLL & p-value \\
\hline TLC \% pred & $65 \pm 20$ & $71 \pm 11$ & $\mathrm{NS}$ \\
FVC \% pred & $64 \pm 17$ & $72 \pm 15$ & $<0.01$ \\
$D \mathrm{~L}, \mathrm{CO} \%$ pred & $44 \pm 15$ & $52 \pm 15$ & $\mathrm{NS}$ \\
$P \mathrm{a}, \mathrm{O}_{2} \mathrm{mmHg}$ & $58 \pm 14$ & $75 \pm 16$ & $<0.005$ \\
$P \mathrm{~A}-\mathrm{a}, \mathrm{O}_{2} \mathrm{mmHg}$ & $49 \pm 14$ & $31 \pm 14$ & $<0.001$ \\
\hline
\end{tabular}

Data are presented as mean \pm SD $(n=16)$. TLC: total lung capacity; FVC: forced vital capacity; $D \mathrm{~L}, \mathrm{CO}$ : diffusing capacity of the lung for carbon monoxide; $\mathrm{Pa}, \mathrm{O}_{2}$ : arterial oxygen tension; $\mathrm{PA}-\mathrm{a}, \mathrm{O}_{2}$ : alveolar to arterial oxygen tension difference; $\%$ pred: percentage of the predicted value; NS: nonsignificant. ${ }^{\#}$ : at 1 week. $(1 \mathrm{mmHg}=0.133 \mathrm{kPa}$.). 




Fig. 2.-Forced vital capacity (FVC) before and after whole lung lavage (WLL) in the 11 patients who completed $\geqslant 3$ yrs of follow-up. Data are presented as mean \pm SD. The course was significant $\left(\mathrm{p}<0.0001\right.$; multivariate analysis of variance). ${ }^{*}: \mathrm{p}<0.05 ; * *: \mathrm{p}<0.01$; ***: $\mathrm{p}<0.001$ (post hoc comparison, versus baseline when not otherwise indicated).

comparison) without significant change thereafter; complete recovery was not achieved in most patients. The overall trend was significant $(\mathrm{p}<0.001)$ (fig. 3).

$P \mathrm{a}, \mathrm{O}_{2}$ and $P \mathrm{~A}-\mathrm{a}, \mathrm{O}_{2}$ improved markedly shortly after WLL (table 2) and tended to increase up to $1 \mathrm{yr}$ without further improvement thereafter; like $D \mathrm{~L}, \mathrm{CO}$, these parameters did not show complete recovery in most patients. The overall trends were highly significant (both $\mathrm{p}<0.001$ ) (fig. 4).

The mean distance in metres covered before exercise interruption was significantly longer at 6 months than at baseline $(\mathrm{p}<0.05,6$ months versus baseline post hoc comparison). This distance tended to increase up to $1 \mathrm{yr}$ and the overall trend was significant $(\mathrm{p}<0.01)$ (fig. 5).

Improvement in all parameters was maintained at the last examination, which was $\geqslant 3$ yrs after the WLL in 11 patients and 7 yrs after WLL in two (table 3 ). The median duration of follow-up in the 11 patients with $\geqslant 3$ yrs of observation was $5 \pm 2$ yrs.

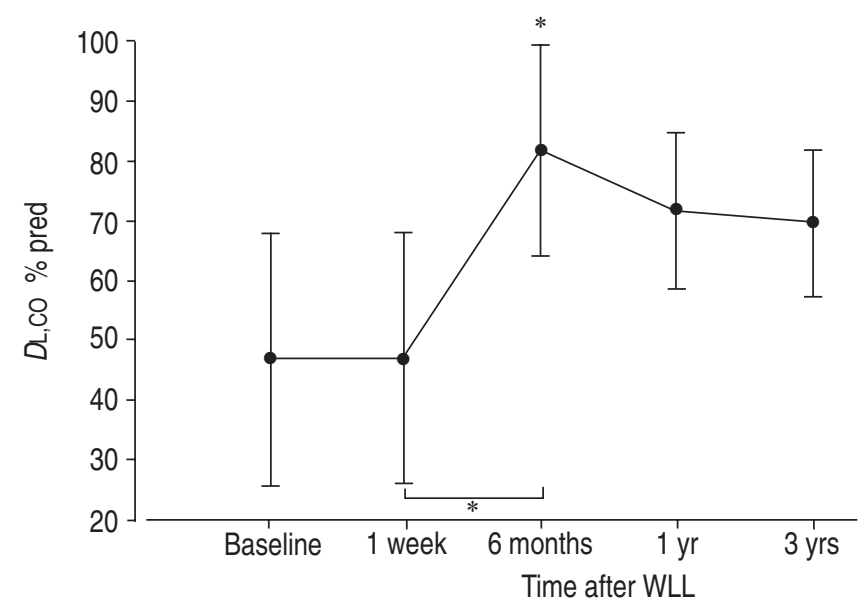

Fig. 3.-Diffusing capacity of the lung for carbon monoxide (DL,CO) before and after whole lung lavage (WLL) in the 11 patients who completed $\geqslant 3$ yrs of follow-up. Data are presented as mean \pm SD. The course was significant $(\mathrm{p}<0.001$; multivariate analysis of variance). $*$ : $\mathrm{p}<0.05$ (post hoc comparison, versus baseline when not otherwise indicated).

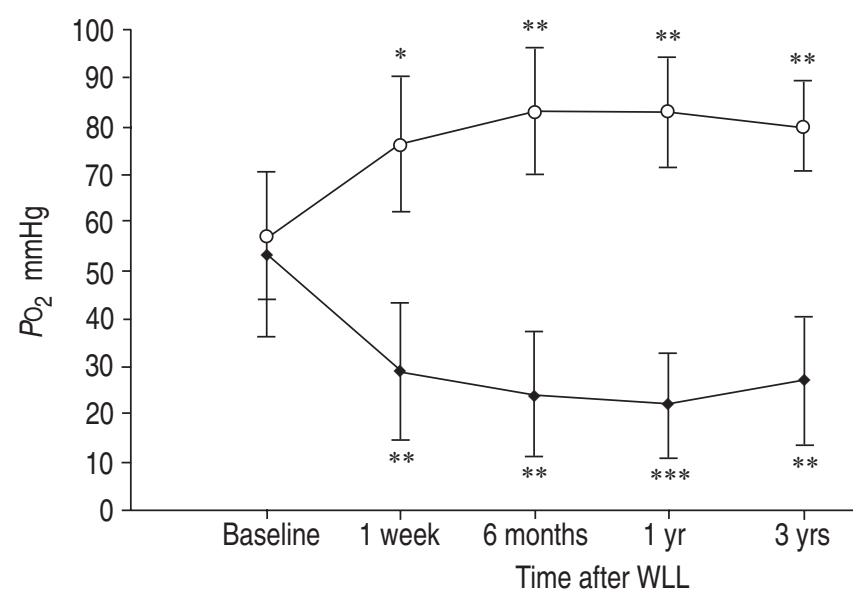

Fig. 4.-Arterial oxygen tension $\left(\mathrm{PO}_{2}\right)\left(\mathrm{Pa}_{\mathrm{a}} \mathrm{O}_{2} ; \bigcirc\right)$ and alveolar to arterial oxygen tension difference $\left(P \mathrm{~A}-\mathrm{a}, \mathrm{O}_{2} ; \bullet\right)$ before and after whole lung lavage (WLL) in the 11 patients who completed $\geqslant 3$ yrs of follow-up. Data are presented as mean \pm SD. The course was significant $(\mathrm{p}<0.001 ;$ multivariate analysis of variance). $*$ : $\mathrm{p}<0.05 ; * *$ : $\mathrm{p}<0.01$; ***: $\mathrm{p}<0.001$ versus baseline (post hoc comparison). $(1 \mathrm{mmHg}=0.133 \mathrm{kPa}$.)

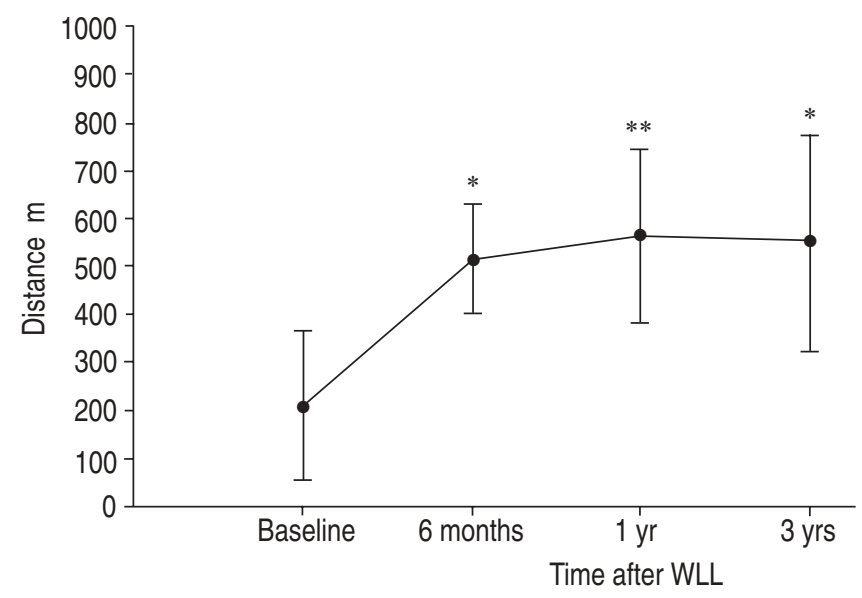

Fig. 5.- Total treadmill distance covered before exercise interruption before and after whole lung lavage (WLL) in the six patients with an arterial oxygen tension of $\geqslant 8.0 \mathrm{kPa}(60 \mathrm{mmHg})$ at baseline who completed $\geqslant 3$ yrs of follow-up. The course was significant $(p<0.01$; multivariate analysis of variance). *: $\mathrm{p}<0.05$; **: $\mathrm{p}<0.01$ (post hoc comparison, versus baseline when not otherwise indicated).

Table 3. - Long-term improvement after whole lung lavage ${ }^{\#}$

\begin{tabular}{lccc}
\hline & Baseline & Last evaluation & p-value \\
\hline TLC \% pred & $65 \pm 21$ & $73 \pm 29$ & NS \\
FVC \% pred & $62 \pm 13$ & $81 \pm 13$ & $<0.001$ \\
$D \mathrm{~L}, \mathrm{CO} \%$ pred & $44 \pm 16$ & $75 \pm 19$ & $<0.005$ \\
$P \mathrm{a}, \mathrm{O}_{2} \mathrm{mmHg}$ & $55 \pm 12$ & $78 \pm 11$ & $<0.0005$ \\
$P \mathrm{~A}-\mathrm{a}, \mathrm{O}_{2} \mathrm{mmHg}$ & $52 \pm 13$ & $27 \pm 11$ & $<0.0001$ \\
Treadmill distance m & $209 \pm 156$ & $626 \pm 264$ & $<0.005$ \\
\hline
\end{tabular}

Data are presented as mean \pm SD $(n=11)$. TLC: total lung capacity; FVC: forced vital capacity; $D \mathrm{~L}, \mathrm{CO}$ : diffusing capacity of the lung for carbon monoxide; $\mathrm{Pa}_{2} \mathrm{O}_{2}$ : arterial oxygen tension; $\mathrm{PA}-\mathrm{a}, \mathrm{O}_{2}$ : alveolar to arterial oxygen tension difference; $\%$ pred: percentage of the predicted value; NS: nonsignificant. \#: at median of $5 \pm 2 \mathrm{yrs}$. $(1 \mathrm{mmHg}=0.133 \mathrm{kPa}$.). 


\section{Discussion}

The major findings of the present study are that WLL is a safe procedure with long-lasting benefit, the proportion of subjects free from recurrent PAP being $>70 \%$ at $7 \mathrm{yrs}$. The bulk of the improvement in spirometric parameters was almost completely gained during the period immediately following WLL due to the efficient clearance of alveolar spaces. The slow and incomplete recovery of $D \mathrm{~L}, \mathrm{CO}$ and the residual gas exchange abnormalities and exercise limitation may be explained on the basis of engorgement of lymphatic vessels within interlobular septa.

No complications during (e.g. hypoxaemia during the emptying phase and haemodynamic instability) or after (e.g. endotracheal granuloma or stenosis, pleural collections and hydropneumothorax) WLL were observed in the present series. Over the time span of the study, the WLL technique improved continuously and the team's experience increased: as a probable consequence, no patient after 1995 in the present series required more than one lavage [4, 8]. Careful assessment during the preparation and WLL, as well as the choice of the nondependent lung lavage procedure, allowed even severely impaired PAP patients to be treated safely and successfully. This may justify the invasive and prolonged nature of the present WLL, i.e. treatment sessions lasting $>4 \mathrm{~h}$ per lung and requiring pulmonary and radial artery catheterisation, bronchodilator infusions and prolonged admission to the intensive care unit, compared to the standard procedures reported in the literature $[5,15]$. Recently, a less cumbersome procedure, bronchofibrescopic lobar lavage, has been proposed for carefully selected patients [16]. Cheng et al. [16] underline the fact that this procedure is safe and does not require anaesthetic support; however, it is recommended only in milder disease, or, conversely, in particularly severe cases in which the physiological derangement of WLL, especially during the drainage phase, would not be tolerated or general anaesthesia would be hazardous [7].

To date, the rarity of PAP has prevented formal prospective studies from elucidating the response to WLL, particularly in terms of the onset and duration of the benefit of such management. One further difficulty in evaluating therapeutic interventions in PAP is the variable natural history of the disorder and its possible, although infrequent, spontaneous resolution. In the present study, no patients showed any improvement in the months prior to WLL. The present study documents a median duration of overall benefit from WLL of $3 \mathrm{yrs}$, with $70 \%$ of patients followed beyond 3 yrs remaining free of recurrent PAP manifestations. In 55 reviewed instances, SEYMOUR and PRESNEILL [5] reported a median duration of clinical benefit of 15 months, with $<20 \%$ of patients followed beyond 3 yrs remaining free of recurrent PAP manifestations. These results should not be too surprising, taking into account the fact that the cases reviewed were from a rather remote period, ranging late 1960s-1980s, at the dawn of the WLL technique [2, 17-20]. In contrast, the present series was collected in the 1990s, when the procedure had already improved considerably [4], and the present refinements to the treatment may explain the improvement in the duration of response to WLL.

The strength of the present lung function follow-up and its analysis lies in the simultaneous measurement of various respiratory parameters. The results allow some speculation to be made as to the mechanism by which WLL acts. With the exception of $D \mathrm{~L}, \mathrm{CO}$, all parameters had improved significantly by 1 week after WLL. The immediate therapeutic efficacy of WLL has been supported by many clinical reports. The major feature of PAP is that the alveoli are flooded with lipoproteinaceous material. Removal of this material by WLL immediately improves lung volumes and probably also the ventilation/perfusion ratio, leading to the remarkable increase in $\mathrm{Pa}, \mathrm{O}_{2}$. Interestingly, the improvement in $D \mathrm{~L}, \mathrm{CO}$, occurring over 6 months, is slower than that of lung volumes and gas exchange. Furthermore, unlike the recovery of lung volumes, the recovery of $D \mathrm{~L}, \mathrm{CO}$ is incomplete in almost all patients at the end of the follow-up. This explains the persistent impairment in gas exchange and exercise tolerance: indeed, $P A-a, O_{2}$ remains in the pathological range and the distance covered during exercise testing is always short considering the relatively young age of the subjects. These data are consistent with the HRCT scan pattern in PAP following WLL, in which, in comparison with pre-WLL features, there is a decrease in the extent of ground-glass opacities but a persistence of reticular opacities and interlobular septal thickening [21]. This pattern may be explained on the basis of engorgement of lymphatic vessels within interlobular septa, providing more efficient clearance from alveolar spaces than before WLL. This could account for the slow recovery of $D \mathrm{~L}, \mathrm{CO}$ and the impairment in gas exchange and exercise tolerance.

There is increasing evidence that idiopathic PAP results from an autoimmune disorder, characterised by antibodies directed against GM-CSF, causing dysfunction of alveolar macrophages [22, 23]. Whether the long-lasting beneficial effect of WLL is simply due to the removal of cellular debris from airspaces or to some interference with the neutralising activity of antibodies directed against GM-CSF remains to be established [8]. Since the late 1990s, reports of single cases or small series have suggested that exogenous GM-CSF appears to benefit adult patients with PAP and may represent an alternative to WLL for treating the disease [24-27]. Recently, SEYMOUR et al. [28] showed, in a study on 14 patients, that a subset of $43 \%$ of their patients with PAP exhibited clinical responses to recombinant GM-CSF therapy, and, in a subsequent paper, SEYMOUR et al. [5] confirmed the benefit in $\sim 50 \%$ of all patients treated to date. Despite these interesting results, a relevant number of patients did not respond and still needed to undergo WLL; moreover, the time needed for improvement in $\mathrm{PA}-\mathrm{a}, \mathrm{O}_{2}$ in responders (i.e. 4-6 weeks) may be too long for patients with severe PAP, and, importantly, the long-term safety of this haematopoietic growth factor and benefits versus costs have not been established $[15,16,29]$. The present findings that three patients required more than one lavage and that, in general, there were residual gas exchange abnormalities and exercise limitation could be interpreted as an indication for considering combined treatment with GM-CSF, a strategy not yet investigated.

In conclusion, whole lung lavage for idiopathic pulmonary alveolar proteinosis is currently a safe procedure in an experienced setting, and yields durable benefit in the majority of patients. Future research should investigate the efficacy of biological therapy with granulocyte-macrophage colonystimulating factor in combination with whole lung lavage, particularly in those patients who respond less well to whole lung lavage and/or require more than one lavage because of recurrence of pulmonary alveolar proteinosis.

\section{References}

1. Mazzone PJ, Thomassen MJ, Kavuru MS. Pulmonary alveolar proteinosis: recent advances. Semin Respir Crit Care Med 2002; 23: 115-126.

2. Prakash UBS, Barham SS, Carpenter HA, Dines DE, Marsh HM. Pulmonary alveolar phospholipoproteinosis: experience 
with 34 cases and a review. Mayo Clin Proc 1987; 62: 499518.

3. Ramirez RJ. Bronchopulmonary lavage: new techniques and observations. Dis Chest 1966; 50: 581-588.

4. Rodi G, Iotti G, Galbusera C, Mencherini S, Raimondi F, Braschi A. Whole lung lavage. Monaldi Arch Chest Dis 1995; 1: $64-66$.

5. Seymour JF, Presneill JJ. Pulmonary alveolar proteinosis. Progress in the first 44 years. Am J Respir Crit Care Med 2002; 166: 215-235.

6. Bingisser R, Kaplan V, Zollinger A, Russi EW. Whole lung lavage in alveolar proteinosis by a modified lavage technique. Chest 1998; 113: 1718-1719.

7. Kavuru MS, Popovich M. Therapeutic whole lung lavage. A stop-gap therapy for alveolar proteinosis. Chest 2002; 122: $1123-1124$.

8. Alberti A, Luisetti M, Braschi A, et al. Bronchoalveolar lavage fluid composition in alveolar proteinosis. Early changes after therapeutic lavage. Am J Respir Crit Care Med 1996; 154: 817-820.

9. Rogers RM, Szidon JP, Shelburne J, Neigh JL, Shuman JF, Tantum KR. Hemodynamic response of the pulmonary circulation to bronchopulmonary lavage in man. $N$ Engl J Med 1972; 286: 1230-1233.

10. Kao D, Wasserman K, Costley D, Benfield JR. Advances in the treatment of pulmonary alveolar proteinosis. Am Rev Respir Dis 1975; 111: 361-363.

11. American Thoracic Society. Lung function testing: selection of reference values and interpretative strategies. Am Rev Respir Dis 1991; 144: 1202-1218.

12. Quanjer PH, Tammeling GJ, Cotes JE, Pedersen OF, Peslin $\mathrm{R}$, Yernault JC. Lung volumes and forced ventilatory flows. Eur Respir J 1993; 6: Suppl. 16, 5-40.

13. Cotes JE, Chinn DJ, Quanjer PH, Roca J, Yernault JC. Standardization of the measurement of transfer factor (diffusing capacity). Eur Respir J 1993; 6: Suppl. 16, 4152.

14. Grossman RF, Frost A, Zamel N, et al. Results of singlelung transplantation for bilateral pulmonary fibrosis. The Toronto Lung Transplant Group. N Engl J Med 1990; 322: 727-733.

15. Shah PL, Hansell D, Lawson PR, Reid KBM, Morgan C. Pulmonary alveolar proteinosis: clinical aspects and current concepts on pathogenesis. Thorax 2000; 55: 67-77.

16. Cheng SL, Chang HT, Lau HP, Lee LN, Yang PC. Pulmonary alveolar proteinosis. Treatment by bronchofiberscopic lobar lavage. Chest 2002; 122: 1480-1485.

17. Du Bois RM, McAllister WAC, Branthwaite MA. Alveolar proteinosis: diagnosis and treatment over a 10-year period Thorax 1983; 38: 360-363.

18. Goldstein LS, Kavuru MS, Curtis-McCarthy P, Christie HA Farver C, Stoller JK. Pulmonary alveolar proteinosis: clinical features and outcome. Chest 1998; 114: 1357-1362.

19. Kariman K, Kylstra JA, Spock A. Pulmonary alveolar proteinosis: a prospective clinical experience in 23 patients for 15 years. Lung 1984; 162: 223-231.

20. Selecky PA, Wasserman K, Benfield JR, Lippmann M. The clinical and physiological effect of whole lung lavage in pulmonary alveolar proteinosis: a ten-year experience. Ann Thorac Surg 1977; 24: 451-461.

21. Lee KN, Levin DL, Webb RW, Chen D, Storto ML, Golden JA. Pulmonary alveolar proteinosis. High-resolution $\mathrm{CT}$, chest radiographic, and functional correlations. Chest 1997; 111: 989-995.

22. Takayuki $\mathrm{K}$, Tanaka $\mathrm{N}$, Watanabe $\mathrm{J}$, et al. Idiopathic pulmonary alveolar proteinosis as an autoimmune disease with neutralizing antibody against granulocyte/macrophage colony-stimulating factor. J Exp Med 1999; 190: 875-880.

23. Bonfield TL, Russell D, Burgess S, Malur A, Kavuru MS, Thomassen MJ. Autoantibodies against granulocyte macrophage colony-stimulating factor are diagnostic for pulmonary alveolar proteinosis. Am J Respir Cell Mol Biol 2002; 27: $481-486$

24. Seymour JF, Dunn AR, Vincent JM, Presneill JJ, Pain MC. Efficacy of granulocyte-macrophage colony-stimulating factor in acquired alveolar proteinosis. N Engl J Med 1996; 335: 1924-1925.

25. Kavuru MS, Sullivan EJ, Piccin R, Thomassen MJ, Stoller JK. Exogenous granulocyte-macrophage colonystimulating factor administration for pulmonary alveolar proteinosis. Am J Respir Crit Care Med 2000; 161: 11431148.

26. Schoch OD, Schanz U, Koller M, et al. BAL findings in a patient with pulmonary alveolar proteinosis successfully treated with GM-CSF. Thorax 2002; 57: 277-280.

27. Barraclough RM, Gillies AJ. Pulmonary alveolar proteinosis: a complete response to GM-CSF therapy. Thorax 2001; 56: 664-665.

28. Seymour JF, Presneill JJ, Schoch OD, et al. Therapeutic efficacy of granulocyte-macrophage colony-stimulating factor in patients with idiopathic acquired alveolar proteinosis. Am J Respir Crit Care Med 2001; 163: 524-531.

29. Seymour JF, Begley CG, Dirksen U, et al. Attenuated hematopoietic response to granulocyte-macrophage colonystimulating factor in patients with acquired pulmonary alveolar proteinosis. Blood 1998; 92: 2657-2667. 